
5

\title{
CRACK PROPAGATION SPEED IN ULTRA HIGH PERFORMANCE
}

CONCRETE (UHPC)

\author{
Sukhoon Pyo $^{\mathrm{a} *}$, Mo Alkaysi ${ }^{\mathrm{b}}$ and Sherif El-Tawil ${ }^{\mathrm{b}}$ \\ ${ }^{a}$ New Transportation Systems Research Center, Korea Railroad Research Institute, 176 Railroad Museum Road, \\ Uiwang-si, Gyeonggi-do, 16105, South Korea \\ ${ }^{b}$ Department of Civil \& Environmental Engineering, University of Michigan, 2350 Hayward, G.G. Brown, \\ Ann Arbor, MI 48109-2125, USA \\ *Corresponding author, E-mail: shpyo@ krri.re.kr, +82-31-460-5413
}

\section{ABSTRACT}

This paper investigates crack speed in ultra-high performance concrete (UHPC) using pre-notched three-point bending specimens. The experimental parameters are fiber volume fraction and rate of loading. A hydraulic servo-controlled testing machine is used to apply lower notch tip strain rates, in the range of 0.025 to $1.01 / \mathrm{s}$, while a newly developed impact testing system is used to achieve higher notch tip strain rates, ranging from 6.8 to $41.11 / \mathrm{s}$. A high-speed camera is used to record images of the UHPC specimens during testing. Notch tip strain and crack speed are computed from the images, which show that crack speed increases asymptotically as the crack initiation strain rate increases. Crack speeds of up to $514 \mathrm{~m} / \mathrm{s}$ were achieved at the lower notch tip strain rates and up to $1454 \mathrm{~m} / \mathrm{s}$ for the higher notch tip strain rates. The achieved relationships are incorporated into a recently proposed crack-velocity dependent dynamic fracture model. The model is validated using published experimental data and used to show that, like conventional concrete, the strain rate sensitivity of UHPC is strongly associated with the characteristics of dynamic crack growth.

Keywords: Crack Speed; Impact Loading; Strain-rate Effects; Ultra High Performance Concrete 


\section{INTRODUCTION}

2 Crack propagation in brittle materials is a key mechanism leading to material failure and is a 3 complex process to analyze, especially under dynamic loading. The main techniques used by

4 researchers to characterize crack propagation are: experiments [1-5], analytical approaches [6-8],

5 and numerical simulations [9-12]. Research on crack propagation was reviewed by Freund [13].

6 In spite of decades of research in this field, there is still controversy regarding fundamental aspects

7 of the dynamic fracture process, such as the observed maximum crack velocity. For example, Xie

8 and Sanderson [14] suggested that the measured crack velocity cannot reach the Rayleigh wave

9 speed (i.e. the theoretically predicted maximum crack speed) because the dynamic stress intensity

10 factor approaches zero when crack velocity is about half of the Rayleigh wave speed. In contrast,

11 Sharon and Fineberg [3] insisted that measured peak crack velocities approach the theoretical

12 predictions if the instantaneous velocity is used instead of the averaged value.

14 Understanding crack speed in a solid is important in dynamic fracture mechanics. This is because,

15 with some assumptions, the stress field near the moving crack tip in linear elastic brittle solids

16 under small-scale yielding can be expressed as a single parameter, the stress intensity factor [5].

17 This suggests that a relationship between crack velocity and the stress intensity factor can be

18 established $[5,15,16]$. A number of analytical and numerical models have been proposed based

19 on the assumption of constant crack velocity at a given strain rate. Landis et al. [8] used an elastic-

20 viscoplastic constitutive law incorporating a rate dependent fracture process zone to explain Mode

21 I steady-state crack growth in strain rate dependent materials. They computed the macroscopic

22 work energy of fracture as a function of crack velocity. Pyo and El-Tawil [17] used experimental

23 data in the literature supplemented by computational models to obtain a relationship between crack 
1 velocity and strain rate in normal concrete. By implementing the developed relationships into

2 crack-speed dependent dynamic fracture models, they predicted the dynamic increase factor of

3 concrete under dynamic tensile loading. Based on the comparison, they suggested that strain rate

4 sensitivity is strongly associated with the characteristics of dynamic crack growth and inertial

5 effects at the boundaries of the crack.

7 Ultra high performance concrete (UHPC) is an advanced cement based composite, which has

8 extremely high compressive strength (over $150 \mathrm{MPa}$ ) and durability, including high resistance to

9 chemical attack, freeze-thaw cycles, abrasion, and chloride penetration [18-20]. Recent work

10 suggests that the mechanical and durability properties of UHPC make it an ideal candidate for use

11 in developing new solutions to pressing concerns about infrastructure deterioration, repair, and

12 replacement [21]. However, to the best knowledge of the authors, no studies have been reported

13 on the crack speed in UHPC under different loading speeds, which motivated this work.

15 In the present study, relationships between crack speed and crack initiation strain rate in UHPC 16 under various rates of loading are established. A hydraulic servo-controlled testing machine and a 17 newly developed impact testing system are is used to apply 'low' and 'high' loading rates, 18 respectively, on pre-notched three-point bending specimens. The Digital Image Correlation (DIC) 19 technique and Canny edge detection algorithm are adopted to compute crack tip strain and crack 20 speed in UHPC specimens. The achieved relationship are incorporated into the crack-velocity 21 dependent dynamic fracture model proposed by Pyo and El-Tawil [17] to predict the DIF of UHPC 22 and compared with experimental data obtained from Pyo et al. [22] and Pyo [23]. 


\section{EXPERIMENTAL PROGRAM}

2 An experimental program was carried out to investigate crack propagation speed in UHPC as a 3 function of notch tip crack initiation strain rate. The mix proportions of UHPC with three different

4 volume fractions of fibers are given in Table 1. Further details about the mix constituents can be

5 found in Wille et al. [24]. Mixes with no fibers were selected to focus attention on the matrix itself.

6 Mixes with higher fiber volume fractions than those shown in Table 1 were not considered because

7 of the concern that crack speed would be too slow to capture in a meaningful manner with a high

8 speed camera. Table 2 lists the properties of the steel fibers used in this study.

A Hobart type laboratory mixer was used to prepare the UHPC mixture. The mixing procedure

11 followed Wille et al. [24]. First, silica fume was mixed with all the sand for approximately 5

12 minutes. Then, cement and glass powder were added and mixed together for at least another 5

13 minutes before the water and superplasticizer were added. The cementitious mixture became fluid 14 after approximately 5 minutes of adding the liquid ingredients. When the cementitious mixture 15 started to show adequate flowability and viscosity, fibers were dispersed by hand into the mix. 16 Once thoroughly mixed, the cementitious mixture was poured into pre-notched three point bending 17 specimen molds without any vibration. After casting, the specimens were covered with plastic 18 sheets and stored at room temperature for 24 hours prior to de-molding. After 27 days of water 19 curing, but without any special curing such as heat or pressure treatment, the UHPC specimens 20 were left to dry in the laboratory environment for at least 24 hours. Cube specimens with 21 dimensions of $50 \times 50 \times 50 \mathrm{~mm}(2 \times 2 \times 2$ in) were also made from each series and tested after 22 curing. The compressive strengths were averaged from at least three cube specimens and are 23 summarized in Table 3. 
1 Table 1. Mixtures proportions by weight (based on Wille et al. [24])

\begin{tabular}{cccc}
\hline Fiber Volume Fraction & $0 \%$ & $0.5 \%$ & $1.0 \%$ \\
\hline Cement & 1.00 & 1.00 & 1.00 \\
\hline Silica Fume & 0.25 & 0.25 & 0.25 \\
\hline Glass Powder & 0.25 & 0.25 & 0.25 \\
\hline Water & 0.22 & 0.22 & 0.22 \\
\hline Superplasticizer & 0.005 & 0.005 & 0.005 \\
\hline Sand $\mathrm{A}^{\dagger}$ & 0.28 & 0.27 & 0.27 \\
\hline Sand $\mathrm{B}^{\S}$ & 1.10 & 1.09 & 1.07
\end{tabular}

${ }^{\dagger}$ Maximum grain size $=0.2 \mathrm{~mm}(1 / 128 \mathrm{in}$.$) .$

${ }^{\S}$ Maximum grain size $=0.8 \mathrm{~mm}(1 / 32$ in. $)$.

4

5 Table 2. Properties of steel fiber used in this study

\begin{tabular}{cc}
\hline Material & Brass coated high carbon steel wire \\
\hline Shape & Cross section: round / length: straight \\
\hline Diameter $(\mathrm{mm})$ & $0.2 \pm 0.01$ \\
\hline Length $(\mathrm{mm})$ & 19.5 \\
\hline Tensile Strength $(\mathrm{MPa})$ & $2450 \sim 2750$ \\
\hline
\end{tabular}

6

7 Table 3. Mechanical and fracture properties of UHPC

\begin{tabular}{cccc}
\hline \multirow{2}{*}{ Test series } & $\begin{array}{c}\text { Compressive stress } \\
(\mathrm{MPa})\end{array}$ & \multicolumn{2}{c}{$\begin{array}{c}\text { Critical stress intensity factor, } \\
K_{I C},(\mathrm{MPa} \sqrt{m})\end{array}$} \\
\cline { 3 - 4 } & 151 & 5.00 & $7.6 \mathrm{~mm} / \mathrm{s}$ \\
\hline CS-0\% & 171 & N/A & $5.46^{\dagger}$ \\
CS-0.5\% & 191 & N/A & 7.19 \\
CS-1.0\% & $19076 \mathrm{~mm} / \mathrm{s}$ & 14.3 \\
\hline
\end{tabular}

$8 \quad$ Calculated from one only experiment because of an error in the data acquisition system

$9 \quad$ while testing.

11 Each test series is designated by its fiber volume fraction; e.g. CS-0.5\% represents a crack speed

12 (CS) mix with $0.5 \%$ fiber volume fraction. Four loading rates are considered in this study. The two

13 lower loading speeds are achieved by using a hydraulic servo-controlled testing system running at 
10.0076 and $7.6 \mathrm{~mm} / \mathrm{s}$. The two faster speeds are achieved using a recently developed impact testing

2 system developed by Pyo and El-Tawil [25] and described later on. The selected loading rates

3 allow for a wide range of crack tip crack initiation strain rates to be achieved. At least three

4 specimens for each series are tested as summarized in Table 4. The lowest loading speed, 0.0076

$5 \mathrm{~mm} / \mathrm{s}$, is used just for the plain UHPC specimens, i.e. CS-0\%, since crack propagation in the fiber

6 reinforced UHPC specimens was too slow to record using the high speed camera.

7

8 Table 4. Number of UHPC specimens investigated in this study

\begin{tabular}{ccccc}
\hline \multirow{2}{*}{ Test series } & \multicolumn{2}{c}{ MTS } & \multicolumn{2}{c}{ Impact Testing System } \\
\cline { 2 - 5 } & $0.0076 \mathrm{~mm} / \mathrm{s}$ & $7.6 \mathrm{~mm} / \mathrm{s}$ & Type 1 coupler & Type 2 coupler \\
\hline CS-0\% & 3 & 4 & 4 & 3 \\
CS- $0.5 \%$ & $\mathrm{X}$ & 3 & 4 & 3 \\
$\mathrm{CS}-1.0 \%$ & $\mathrm{X}$ & 3 & 4 & 3 \\
\hline
\end{tabular}

9

Fig. 1 shows a schematic of the pre-notched three-point bending specimen used in this study. The specimen is sized after John et al. [26], who used it in a 3 point bending configuration for measurement of crack speed in mortar. Fig. 2 shows a typical UHPC specimen. The specimen is painted white to enhance crack detection. Random speckle patterns are applied on both sides of

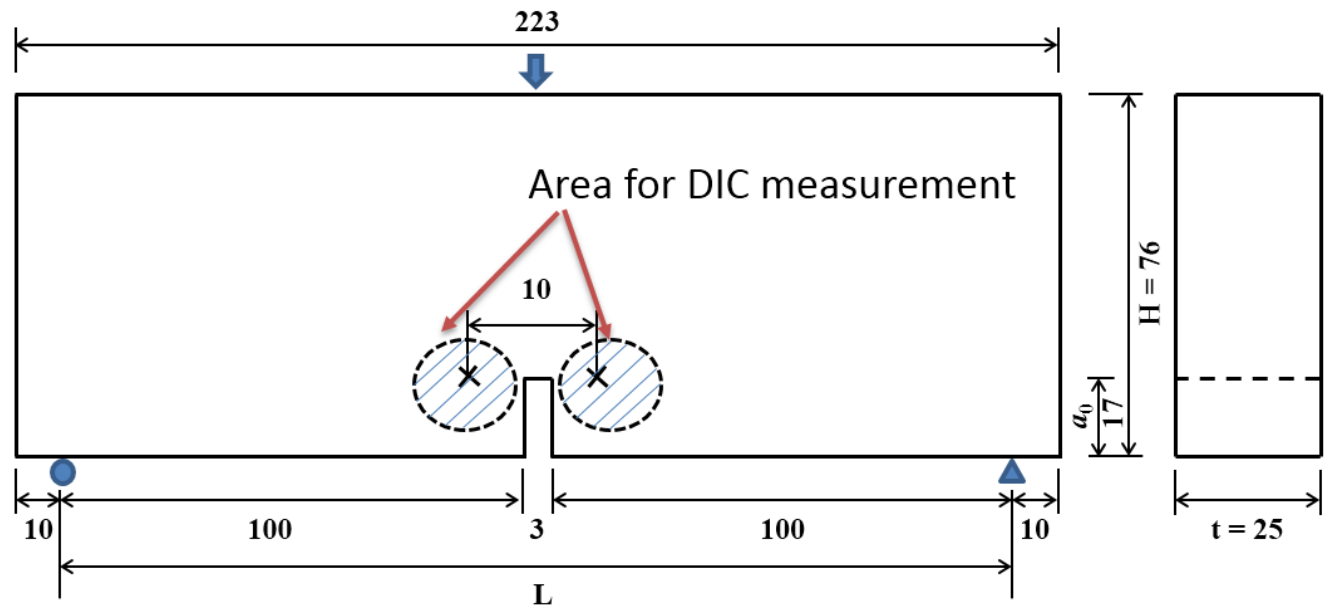

Fig. 1. Schematic of the specimen employed in the crack speed study (unit: mm) 


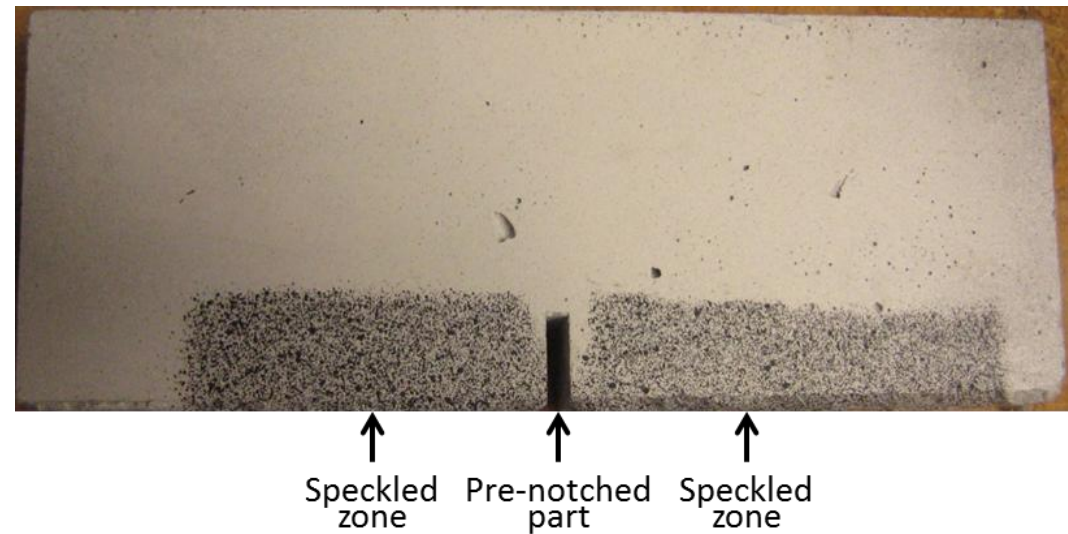

Fig. 2. Actual UHPC specimen

$4 \quad$ Fig. 3. Test setup for three-point bending testing using a hydraulic servo-controlled testing machine 5

6 the notch tip so that notch tip strain can be computed using the DIC technique. The DIC data is

7 first used to measure displacement along the gage length shown in Fig. 1, then notch tip strain is 8 computed from the displacement data by simply dividing displacement by gage length $(10 \mathrm{~mm})$.

9 The assumption is that the initial crack is vertical and driven by the horizontal component of strain 
1 at the notch tip. This follows, in spirit, the process used by John et al. [26], although they used a

2 strain gage attached to the notch tip to measure strain. Fig. 3 shows the test setup within the 3 hydraulic servo-controlled testing system (MTS-810).

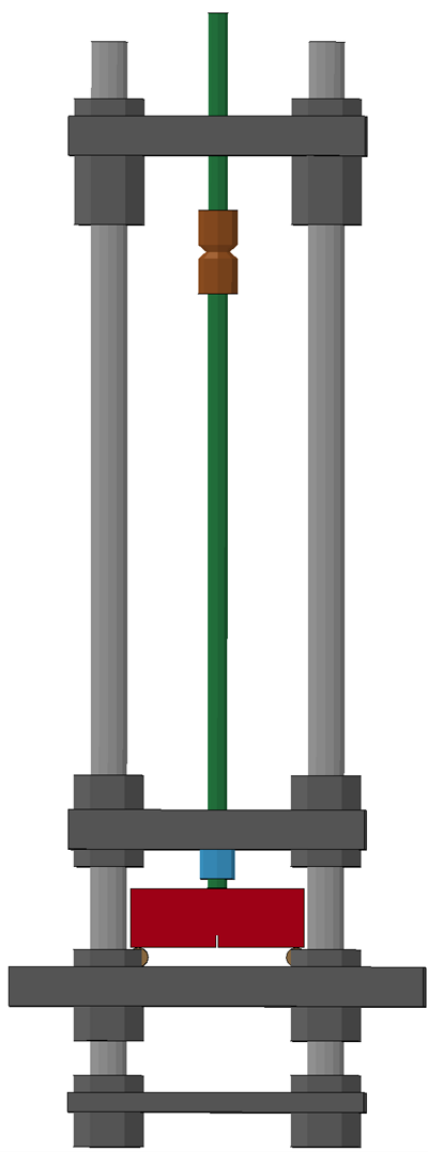

(a) FE model

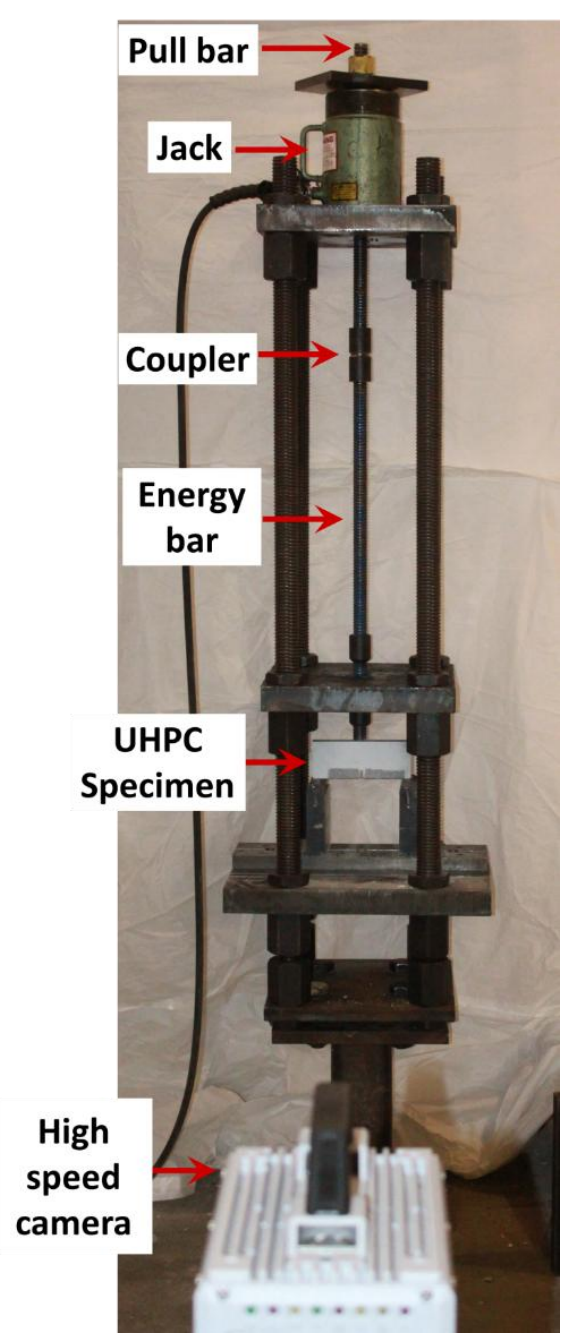

(b) Built prototype

Fig. 4. Impact testing system for crack propagation

5

6 An impact testing system developed by Pyo and El-Tawil [25] was modified to accommodate the new three-point bending test. Fig. 4a shows a FE model that was utilized by Pyo [23] to design the modifications and Fig. $4 \mathrm{~b}$ shows the built prototype. The way by which the modified setup works is similar to the original system developed in Pyo and El-Tawil [25] for impact testing of tensile 
1 specimens. When displacement is applied to the pull bar, the energy bar stores elastic energy. After

2 failure of the coupler, which is notched, the stored elastic energy in the energy bar is suddenly

3 released and transmitted to the specimen in the form of a load pulse. The coupler notch depth is

4 selected so that fracture of the coupler occurs at a given load in order to control the level of the

5 pulse and therefore impact speed. In this experiment, two different notch depths (designated Type

$6 \quad 1$ and Type 2) are considered in order to vary the impact demand on the specimen. Type 2 couplers

7 are notched less than Type 1 resulting in greater stored energy and hence greater impact speed.

8 Notch tip strain and crack speed are calculated by post-processing images of the specimen obtained

9 using the high speed camera.

\section{3. CRACK SPEED ANALYSIS}

12 The images obtained from the high speed camera are post-processed to measure crack tip 13 displacement, which enables calculation of the crack tip speed. In order to extract crack length 14 data from the images, each frame is first queued into an image processing program that runs an 15 edge detection algorithm. Edge detection is achieved using a mathematical method which 16 identifies points in a digital image at which the image brightness changes sharply, signifying a

17 crack edge. For this study, the Canny edge detection algorithm [27] was implemented because it 18 has been shown that it performs better than other methods under almost all scenarios [28].

20 Applying the Canny algorithm results in a binary image which contains a matrix of pixels marked 21 as either an edge pixel or a non-edge pixel. Processing the edge pixels results in characterization 22 of the crack in terms of pixels. The actual length of the crack is computed by using a scale factor 23 that correlates the pixels count to a known dimension. Since the frame rate at which the camera 
1 records the images is known, the time in between increments in crack length is determined and

2 used for computation of the crack tip speed.

3

4 4. EVALUATION OF EXPERIMENTAL RESULTS

$5 \quad 4.1$ Critical Stress Intensity Factor

6 Experimental results from the low rate tests are used to determine the critical stress intensity factor,

$7 \quad K_{I C}$, which is a key parameter that characterizes crack stability under service loads and provides a

8 measure of the effectiveness of steel fiber reinforcement in UHPC. The critical stress intensity

9 factor for a pre-notched three-point bending specimen is calculated using Eq. (1) [29, 30]:

10

$$
K_{\mathrm{IC}}=\sigma_{\mathrm{NC}} \sqrt{\pi a_{0}} f_{1}\left(\alpha_{0}\right)
$$

11 in which

$$
f_{1}(\alpha)=\frac{1.99-\alpha(1-\alpha)\left(2.15-3.93 \alpha+2.7 \alpha^{2}\right)}{\sqrt{\pi}(1+2 \alpha)(1-\alpha)^{3 / 2}}
$$

13 and $\alpha=\frac{a_{0}}{H}, \sigma_{N C}=\frac{3 P_{\max } L}{2 t H^{2}}$ and $P_{\max }$ is the maximum measured load plus the self-weight of the

14 tested beam. All dimensions are given in Fig. 1.

15

16 The computed results of the critical stress intensity factor are given in Table 3 . It should be noted

17 that only one value for the load data was recorded in CS- $0 \%$ for the $7.6 \mathrm{~mm} / \mathrm{s}$ loading speed 18 because of error in the data acquisition system while testing. It can be seen that the critical stress 19 intensity factor increases substantially as fiber volume fraction increases, i.e. $31.8 \%$ and $162 \%$ 20 increase for $\mathrm{CS}-0.5 \%$ and $\mathrm{CS}-1.0 \%$ series compared to CS-0\%, respectively. In contrast, the 21 compressive strength increases by $13.6 \%$ and $26.8 \%$ in CS- $0.5 \%$ and CS-1.0\% compared to CS- 
$10 \%$. As many researchers have already stated [31, 32], these results confirm that fiber

2 reinforcement has a greater effect on fracture toughness than on compressive strength.

3

4 Fig. 5 shows examples of load curves for the low loading rate cases. It can be seen from Fig. 5 that

5 CS- $0 \%$ shows brittle failure without a significant softening region, and thus shows fast crack speed

6 even under low loading rates. In contrast, CS- $0.5 \%$ and CS-1.0\%, show somewhat more ductile

7 failure patterns, allowing large energy dissipation and leading to slower crack speed under the low

8 loading speed regime. Such different failure patterns with and without fiber reinforcements can

9 also be found in the literature [31, 33, 34].

10

11
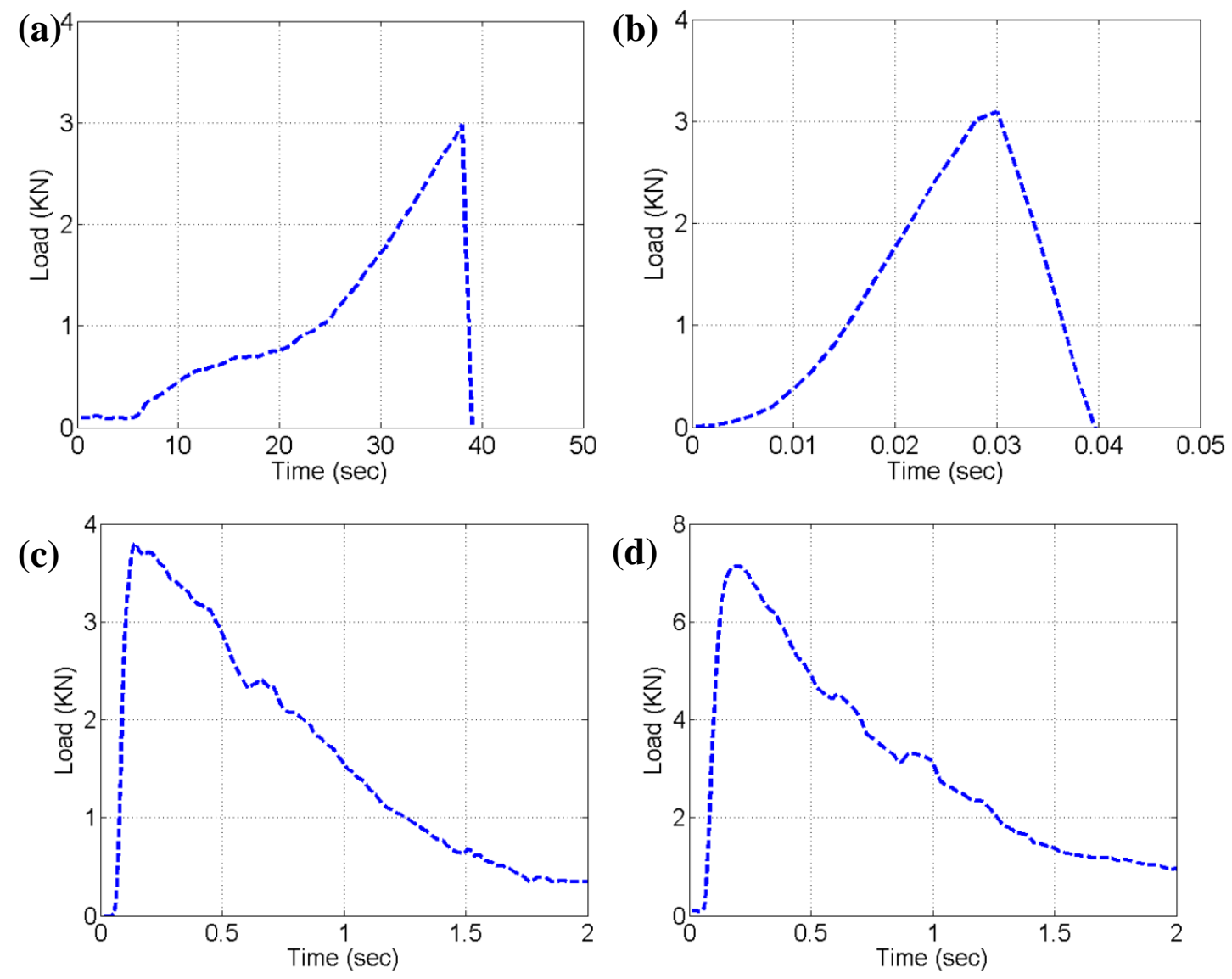

Fig. 5. Examples of load curves for the slow loading cases: (a) CS-0\% tested at $0.0076 \mathrm{~mm} / \mathrm{s}$; (b) CS- $0 \%$ tested at $7.6 \mathrm{~mm} / \mathrm{s}$; (c) CS- $0.5 \%$ tested at $7.6 \mathrm{~mm} / \mathrm{s}$; (d) CS $-1 \%$ tested at $7.6 \mathrm{~mm} / \mathrm{s}$ 
2 The high speed camera used to capture images of crack growth runs at 75,000 frames per second

3 with a resolution of $256 \times 256$ pixels when low rate loading is applied (during testing with the

4 hydraulic servo-controlled testing machine) and at 150,000 frames per second with a resolution of $5256 \times 144$ pixels when fast loading is applied (during testing with the impact machine). Fig. 6 shows

6 examples of the captured crack propagation images in CS-0\%, CS- $0.5 \%$ and CS-1.0\% under

7 various loading speeds. Crack initiation strain rate is computed as an average of the strain time

8 history during which strain increases from zero to the point where the first crack initiates, typically

9 at about $0.0165 \%$ strain. This condition corresponds to the point at which there is a sudden change

10 in the slope of the strain versus time plots in Fig. 7. This also follows in spirit the process used by

11 John et al. [26]. Fig. 7 shows examples of the strain rate calculations, while Table 5 summarizes

12 the obtained rate results.

14 Crack speed is calculated by averaging the slope of the crack length curves (see Fig. 8). The edge

15 detector was used to find the topology of the crack, including the crack tip. Fig. 9 shows an 16 example of crack edge detection using the Canny edge detector. It can be seen in Fig. 9 that the 17 crack edge detector algorithm is capable of accurately detecting the observed crack edges/tips. Fig. 188 illustrates examples of crack speed histories and averaged speeds. Table 5 summarizes all crack 19 speed results from the experiments while Fig. 10 shows the calculated relationships between crack 20 speed and crack initiation strain rate for UHPC.

21

22 For the purpose of reference, the theoretical crack speed (i.e. the Rayleigh wave speed) is also 23 plotted in the figure. The Rayleigh wave speed for compressible isotropic elastic solids can be 


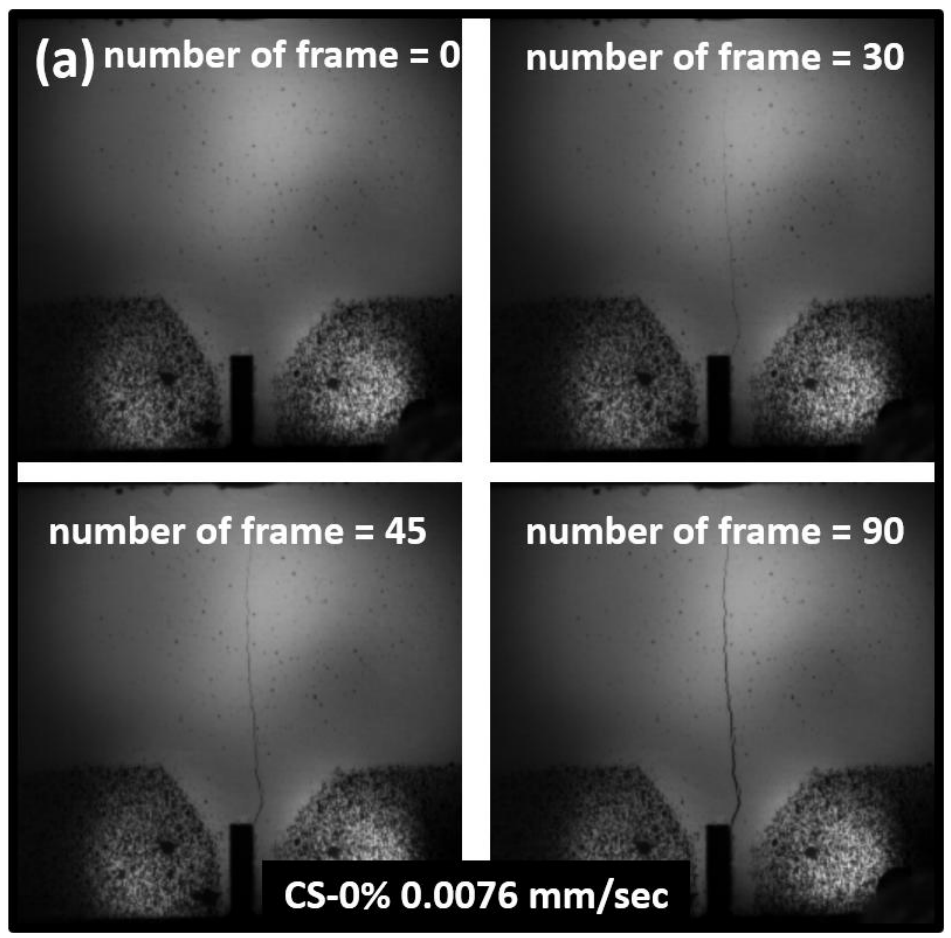

2

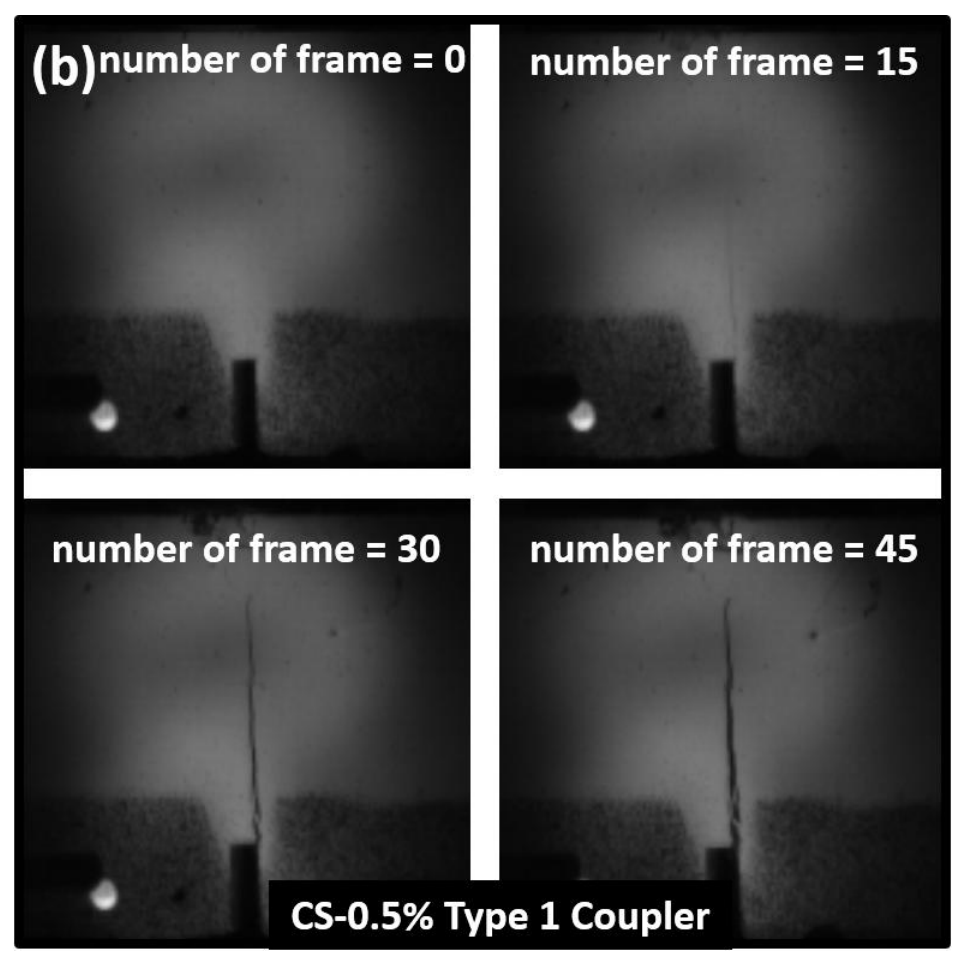

4

5 Fig. 6. Examples of crack propagation under various loading speed: (a) CS-0\% specimen with $0.0076 \mathrm{~mm} / \mathrm{s}$ (using MTS machine); (b) CS-0.5\% specimen with Type 1 coupler using the impact testing system 
1 Table 5. Summary of crack speed results

\begin{tabular}{|c|c|c|c|c|c|c|c|}
\hline $\begin{array}{c}\text { Test } \\
\text { series }\end{array}$ & $\begin{array}{c}\text { Loading speed } \\
\text { in MTS } \\
(\mathrm{mm} / \mathrm{s}) \\
\end{array}$ & $\begin{array}{c}\text { Crack } \\
\text { initiation strain } \\
\text { rate }(1 / \mathrm{s})\end{array}$ & $\begin{array}{l}\text { Crack } \\
\text { speed } \\
(\mathrm{m} / \mathrm{s}) \\
\end{array}$ & $\begin{array}{c}\text { Test } \\
\text { series }\end{array}$ & $\begin{array}{l}\text { Coupler type in } \\
\text { the impact } \\
\text { testing system }\end{array}$ & $\begin{array}{c}\text { Crack } \\
\text { initiation strain } \\
\text { rate }(1 / \mathrm{s})\end{array}$ & $\begin{array}{l}\text { Crack } \\
\text { speed } \\
(\mathrm{m} / \mathrm{s}) \\
\end{array}$ \\
\hline \multirow{2}{*}{ CS-0\% } & 0.0076 & $\begin{array}{l}0.0255 \\
0.0424 \\
0.0589\end{array}$ & $\begin{array}{l}135 \\
206 \\
306\end{array}$ & \multirow{2}{*}{ CS-0\% } & Type 1 & $\begin{array}{l}16.0 \\
19.3 \\
20.9 \\
24.9\end{array}$ & $\begin{array}{c}1117 \\
1420 \\
876 \\
1058\end{array}$ \\
\hline & 7.6 & $\begin{array}{c}0.102 \\
0.205 \\
0.364 \\
1.04\end{array}$ & $\begin{array}{l}514 \\
510 \\
255 \\
283\end{array}$ & & Type 2 & $\begin{array}{l}14.5 \\
18.3 \\
32.5\end{array}$ & $\begin{array}{c}1201 \\
963 \\
1013\end{array}$ \\
\hline \multirow[t]{2}{*}{ CS- $0.5 \%$} & \multirow[t]{2}{*}{7.6} & \multirow{2}{*}{$\begin{array}{c}0.0347 \\
0.0798 \\
0.203\end{array}$} & \multirow{2}{*}{$\begin{array}{l}3.61 \\
15.0 \\
3.98\end{array}$} & \multirow[t]{2}{*}{ CS- $0.5 \%$} & Type 1 & $\begin{array}{l}6.79 \\
13.7 \\
20.1 \\
21.3\end{array}$ & $\begin{array}{c}954 \\
1079 \\
1454 \\
1123\end{array}$ \\
\hline & & & & & Type 2 & $\begin{array}{l}12.5 \\
20.9 \\
41.1\end{array}$ & $\begin{array}{c}1442 \\
1302 \\
827\end{array}$ \\
\hline \multirow[t]{2}{*}{ CS-1.0\% } & \multirow[t]{2}{*}{7.6} & $\begin{array}{c}0.0408 \\
0.108\end{array}$ & $\begin{array}{l}1.90 \\
1.32\end{array}$ & \multirow[t]{2}{*}{ CS-1.0\% } & Type 1 & $\begin{array}{l}12.0 \\
13.8 \\
17.2 \\
20.5\end{array}$ & $\begin{array}{l}1118 \\
1380 \\
1126 \\
1406\end{array}$ \\
\hline & & 0.200 & 4.12 & & Type 2 & $\begin{array}{l}18.6 \\
23.1 \\
33.0\end{array}$ & $\begin{array}{l}1009 \\
1072 \\
1127\end{array}$ \\
\hline
\end{tabular}

2

3 calculated by Eq. (3) [36, 37]:

$4 \quad(2-x)^{2}=4 \sqrt{1-x} \sqrt{1-\gamma x}$

5 where

$6 \quad x=\frac{c^{2}}{c_{2}^{2}}, \quad c_{2}^{2}=\frac{\mu}{\rho}, \quad 0<x<1, \quad 0<\gamma \equiv \frac{\mu}{\lambda+2 \mu}<1$

7 and $\rho$ is the mass density of the material, $c$ is the Rayleigh wave speed and $\mu$ and $\lambda$ are the

8 classical Lamé moduli. For UHPC with $E=50 \mathrm{GPa}, v=0.18, \rho=2,550 \mathrm{~kg} / \mathrm{m}^{3}[18]$, the Rayleigh

9 wave speed is $2616 \mathrm{~m} / \mathrm{s}$, where $E$ is Young's modulus and $v$ is Poisson's ratio. Experimental results

10 obtained by Zhang et al. [35] are also plotted in Fig. 10 for comparison. The results are comparable 
1 with the experimental results obtained in this study despite the fact that Zhang et al. [35] tested a

2 different concrete material and used a different testing configuration.

(a)

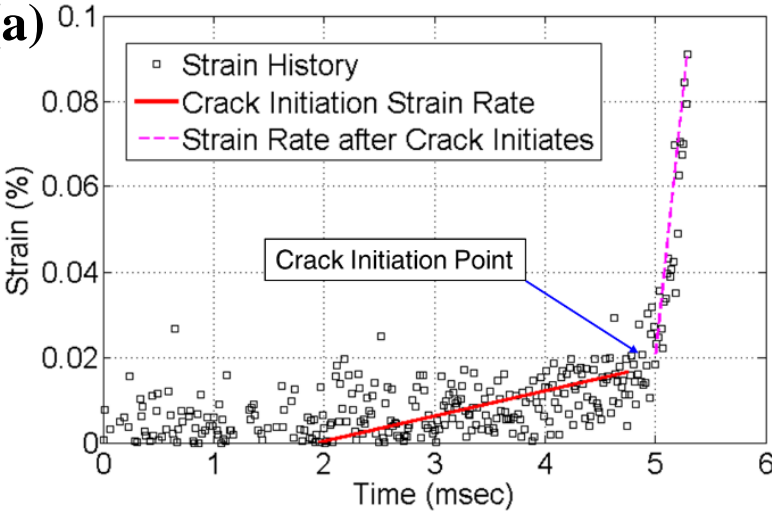

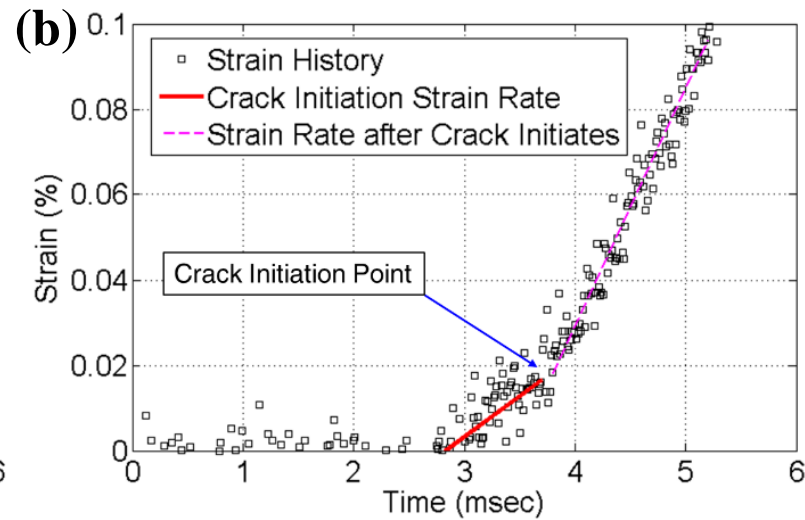

Fig. 7. Examples of strain rate calculations: (a) CS-0\% tested at $0.0076 \mathrm{~mm} / \mathrm{s}(\dot{\varepsilon}=0.05891 / \mathrm{s})$; (b) CS $-0.5 \%$ tested at $7.6 \mathrm{~mm} / \mathrm{s}(\dot{\varepsilon}=0.2031 / \mathrm{s})$

Several observations can be made from Fig. 10. The UHPC series with fiber reinforcement show much lower crack speed than UHPC without fibers at the lower loading speeds (achieved using the MTS hydraulic machine), which indicates that steel fiber reinforcement plays an important role in resisting crack opening at such speeds. In contrast, all UHPC series show similar crack speeds at higher loading rates, suggesting that cracking is independent of fiber reinforcement at these higher loading rates - although the CS-0\% series fails right after crack propagation, while CS- $0.5 \%$ and CS-1.0\% series continues to resist load after matrix cracking, up to the point where fibers are pulled-out from the matrix. Fig. 10 also shows that crack speed increases asymptotically as crack initiation strain rate increases, which can be effectively described as a logarithmic function [17], and that the maximum asymptotic crack speed is below the theoretical maximum. The experimentally obtained data can be fitted as: 
(a)

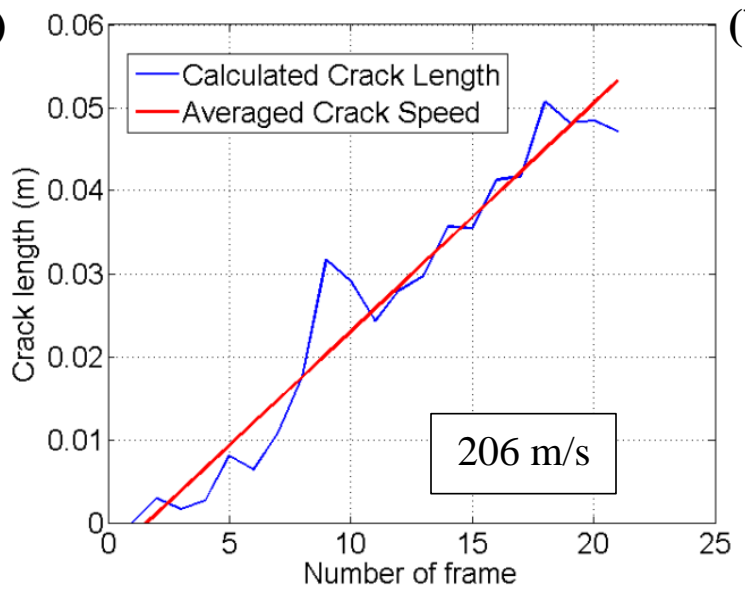

(c)

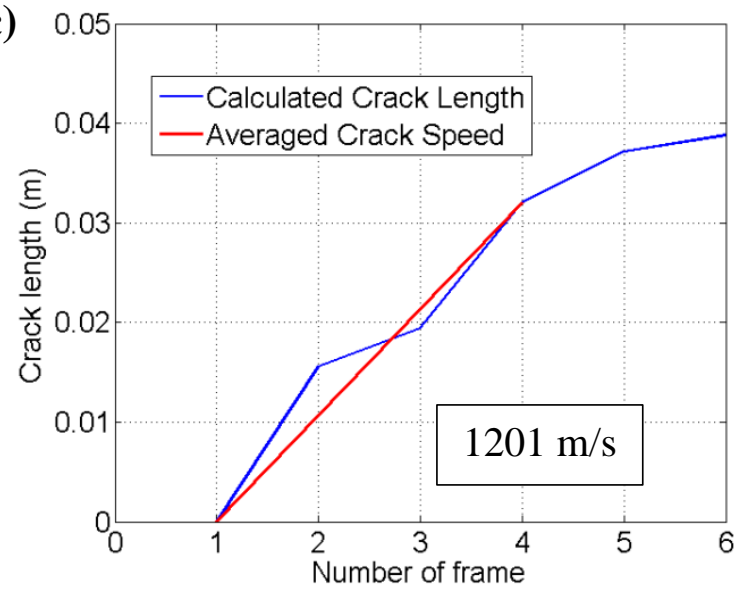

(b)

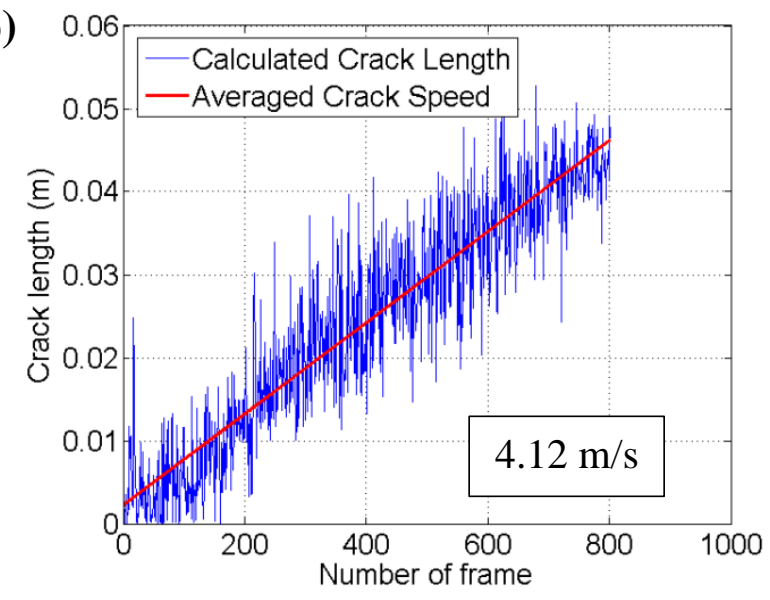

(d)

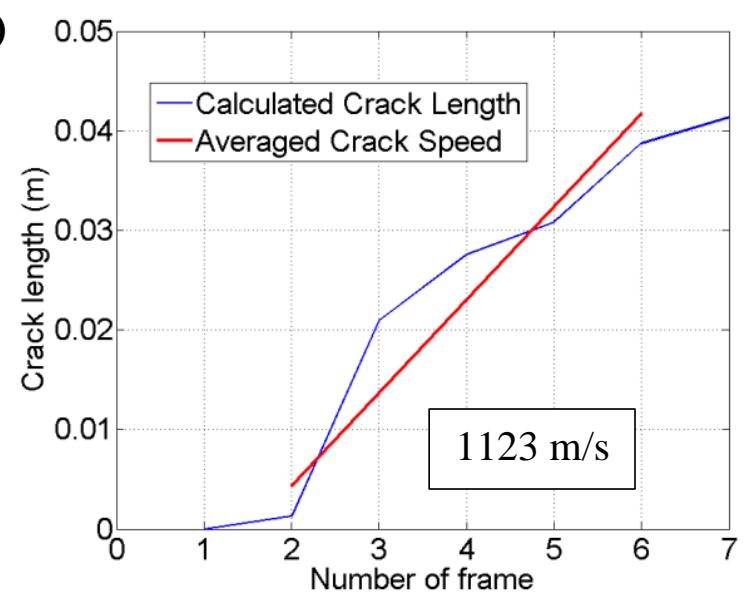

6

$$
v=323 \log (\dot{\varepsilon})+657, \quad R^{2}=0.852 \quad \text { for CS }-0 \%
$$

$$
v=470 \log (\dot{\varepsilon})+567, \quad R^{2}=0.829 \quad \text { for } \mathrm{CS}-0.5 \%
$$

$$
v=494 \log (\dot{\varepsilon})+535, \quad R^{2}=0.914 \quad \text { for CS }-1.0 \%
$$

Fig. 8. Examples of calculated crack speeds: (a) CS-0\% tested at $0.0076 \mathrm{~mm} / \mathrm{s}$; (b) CS-1.0\% tested at $7.6 \mathrm{~mm} / \mathrm{s}$; (c) CS-0\% tested using Type 2 coupler using the impact testing system; (d) CS-0.5\% tested using Type 1 coupler using the impact testing system

\subsection{Discussion}

It was found after visually examining the crack surfaces of all UHPC specimens that there were no noticeable changes in the features of the crack surfaces as a function of crack speed. This is 
1 unlike brittle plastic materials, e.g. polymethylmethacrylate (PMMA) where the fracture surface

2 is featureless up to a certain crack speed and appears jagged thereafter [38]. It was also found that

3 single straight cracks developed predominantly in CS-0\% specimens. In contrast, cracks that

4 followed an irregular path occurred in CS-1.0\% specimens, which is attributed to the effects of the

5 fibers. Details of the failure surfaces can be found in Pyo [23]. It was noted from examining the

6 specimens that fibers were generally oriented randomly, albeit aligned in the plane of the specimen.

7 The preferential alignment is attributed to the relatively thin geometry of the specimen $(25 \mathrm{~mm})$.

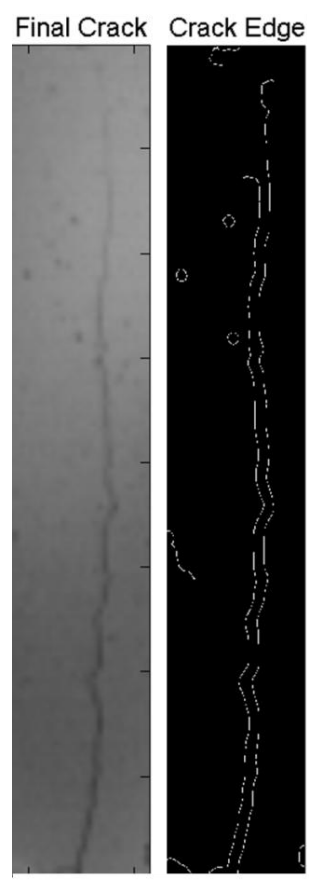

(a)

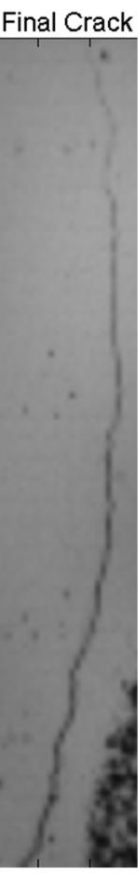

(b)

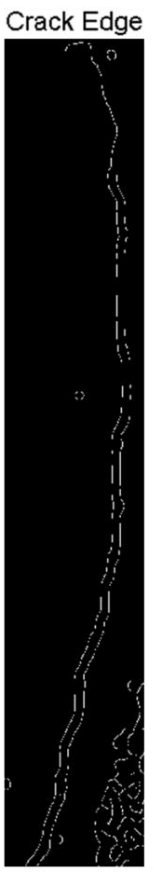

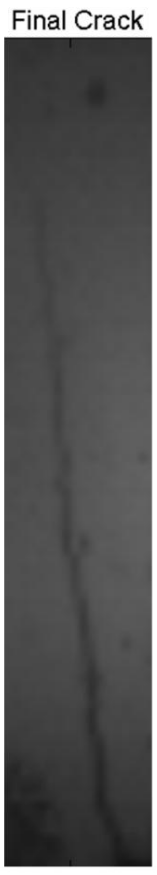

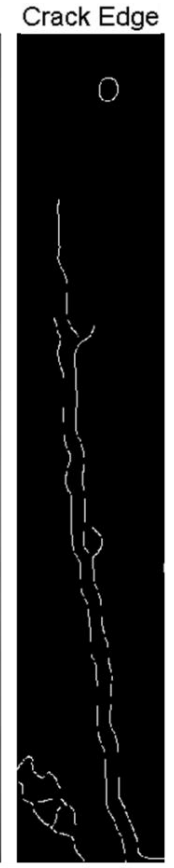

(c)

11 Fig. 9. Examples of the final cracking stages in captured and processed images for CS-0\% specimens under various loading speed: (a) $0.0076 \mathrm{~mm} / \mathrm{s}$ (using the MTS machine); (b) 7.6 $\mathrm{mm} / \mathrm{s}$ (using the MTS machine); (c) Type 1 coupler (using the impact testing system) 
2 The achieved relationships (Eq. 5) between crack speed and crack initiation strain rate of UHPC

3 are incorporated into the DIF model proposed by Pyo and El-Tawil [17], which is based on a crack-

4 velocity dependent dynamic fracture mechanics model [39]. The DIF model was originally

5 developed by Pyo and El-Tawil [17] to explain the DIF of conventional concrete under direct

6 tension as shown in Eq. (6).

$7 \quad D I F=\frac{\sigma_{c}^{d}}{\sigma_{c}^{*}}=\frac{K_{I c}^{d} / \zeta(v) \sqrt{\pi l / 2}}{K_{I c}^{*} / \sqrt{\pi l / 2}}=\frac{1}{\zeta(v)}$

8
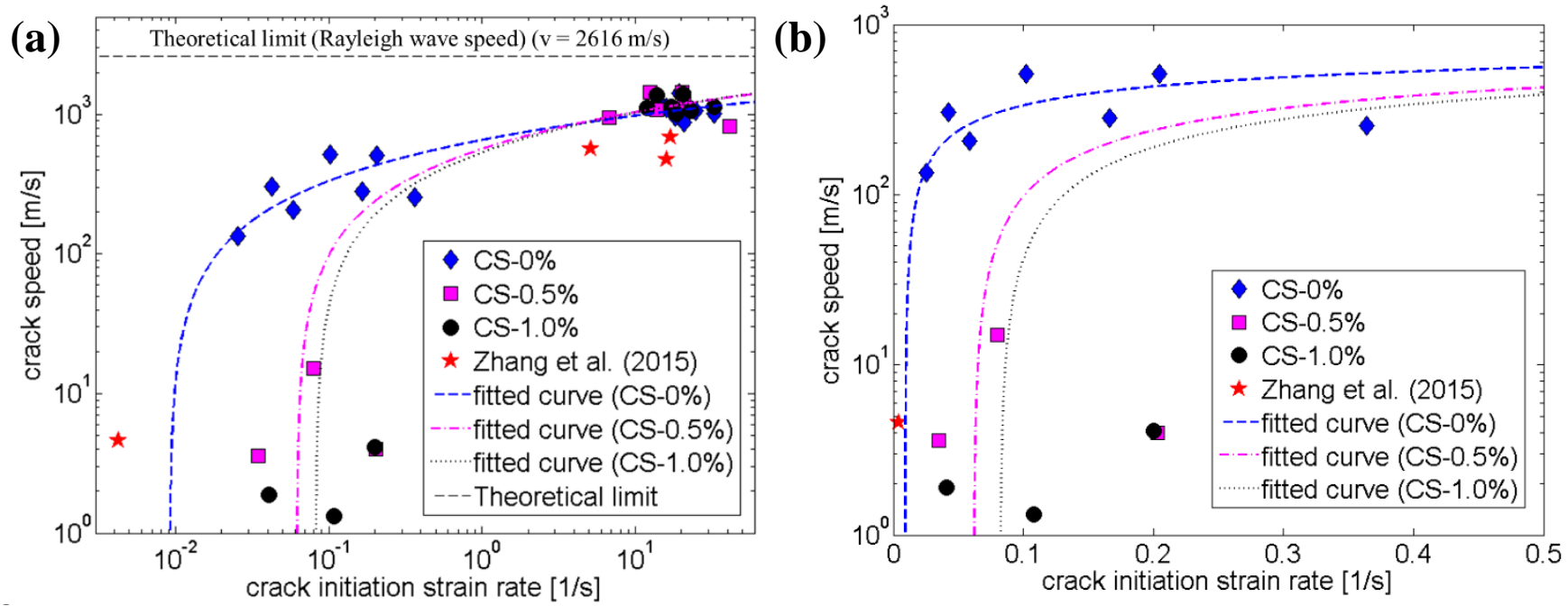

Fig. 10. Calculated crack speed as a function of crack initiation strain rate and compared with similar experimental data in the literature [35]: (a) including high strain rate results; (b) without high strain rate results

where, $l$ is a crack length. $\sigma_{c}^{d}$ and $\sigma_{c}^{*}$ are the critical stresses in the dynamic and static cases, respectively. $K_{I c}^{d}$ and $K_{I c}^{*}$ are critical stress intensity factors in the dynamic and static cases, respectively. In this study, $K_{I c}^{d}$ and $K_{I C}^{*}$ are assumed to be the same following Pyo and El-Tawil [17]. And $\zeta(v)=K_{I}^{d} / K_{I}^{*}$ is a function correlating between dynamic stress intensity factor $\left(K_{I}^{d}\right)$ 
1 and static stress intensity factor $\left(K_{I}^{*}\right)$, which is a function of crack speed, $v$. Pyo and El-Tawil [17]

2 adopted Gao [6]'s approximation for $\zeta(v)=\left(1-v / c_{R}\right) \sqrt{1-v / c_{d}}$. Here, $c_{R}$ and $c_{d}$ are

3 Rayleigh surface wave speed and the dilatational wave speed, respectively. The details of the 4 theoretical model can be found in Pyo and El-Tawil [17].

5

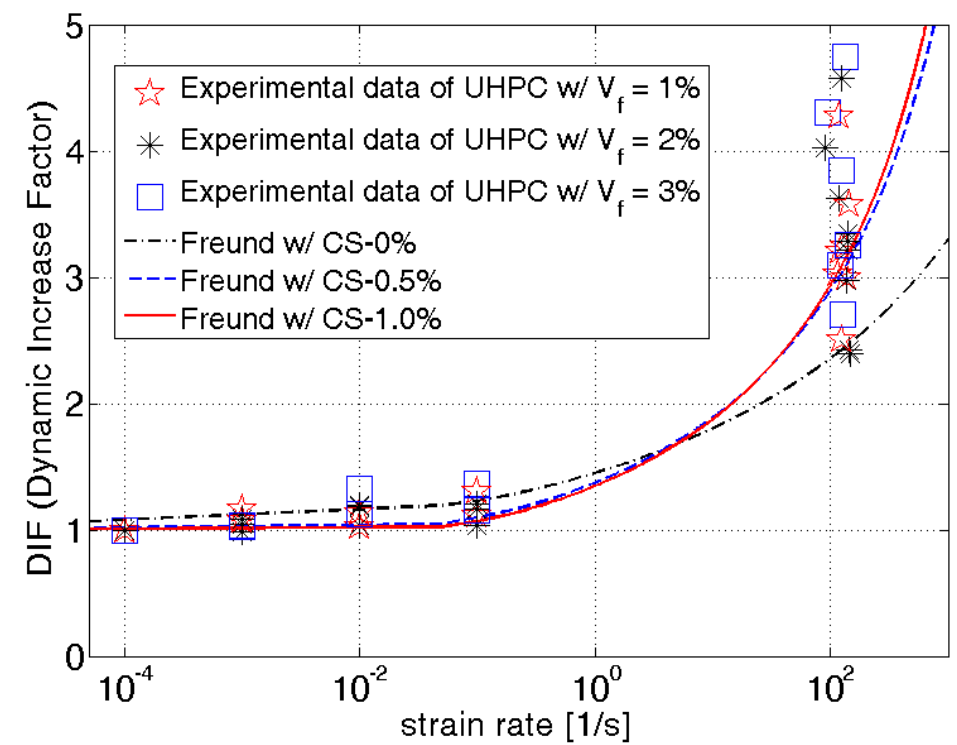

Fig. 11. Comparison between experimental DIF data for UHPC obtained in Pyo et al. [22] and Pyo [23], and the dynamic fracture mechanics model proposed by Pyo and El-Tawil [17]

The results using the DIF model incorporated into the relationships between crack speed and crack initiation strain rate of UHPC obtained herein (Eq. 5) are plotted in Fig. 11 to contrast with the experimental results obtained in Pyo et al. [22] and Pyo [23]. In these studies, UHPC tensile specimens with various types of steel fibers and fiber volume fractions $\left(\mathrm{V}_{\mathrm{f}}\right)$ ranging from one to three percent were tested at various strain rates and the experimentally obtained DIF data under tension were presented. Clearly, there is reasonable correlation between the prediction and the experimentally measured DIF data, which suggests that, like conventional concrete, the DIF of UHPC is also strongly associated with the characteristics of dynamic crack growth. 


\section{CONCLUSION}

3 This experimental study investigated crack propagation in UHPC using three-point bending

4 specimens subjected to a wide range of loading speeds. A hydraulic servo-controlled testing

5 machine was used to generate 'low' loading speeds, while the impact testing system developed in

6 Pyo and El-Tawil [25], was modified to achieve 'fast' loading speeds. The DIC technique and

7 Canny edge detector technique were used to evaluate notch tip strain and crack speed, respectively.

8 The relationships between crack speed and crack initiation strain rate for UHPC were presented

9 based on the test data. Critical stress intensity factors for UHPC were computed to show the

10 effectiveness of fiber reinforcement in UHPC under bending loading. The observations and

11 findings of this study can be summarized as follows:

- The modified impact testing system was able to successfully perform three-point bending testing of UHPC under impact loading.

- Crack initiation strain rates ranging from 0.025 to $1.01 / \mathrm{s}$ and from 6.8 to $41.1 \mathrm{1} / \mathrm{s}$ were experimentally achieved using a hydraulic servo-controlled testing machine and the modified impact testing system, respectively. Crack speeds of up to $514 \mathrm{~m} / \mathrm{s}$ were achieved in the former and up to $1454 \mathrm{~m} / \mathrm{s}$ in the latter. without fibers. However, at high loading rates, crack speeds were insensitive to the amount 
5

of fibers in the specimens. In addition, the critical stress intensity factor increases substantially as fiber volume increases from $0.5 \%$ to $1.0 \%$.

- The crack-velocity dependent dynamic fracture mechanics based DIF model incorporated into the relationships between crack speeds and crack initiation strain rate of UHPC reasonably predicts the experimentally obtained DIF of UHPC in Pyo et al. [22] and Pyo [23]. This suggests that, like conventional concrete, the DIF of UHPC is strongly associated with the characteristics of dynamic crack growth.

\section{ACKNOWLEDGMENTS}

The research described herein was sponsored by the National Science Foundation under Grant No. CMS 0928193 and the University of Michigan, Ann Arbor. The first author was partially supported by a grant from R\&D Program of the Korea Railroad Research Institute, Republic of Korea. The opinions expressed in this paper are those of the authors and do not necessarily reflect the views of the sponsors.

\section{REFERENCES}

[1] Shukla A, Nigam H. A note on the stress intensity factor and crack velocity relationship for Homalite 100. Eng Fract Mech 1986; 25: 91-102.

[2] Dally JW, Agarwal RK, Sanford RJ. A study of hysteresis in the $\mathrm{K}_{\mathrm{ID}}-\dot{a}$ relation. Exp Mech 1990; 30: 177-183.

[3] Sharon E, Fineberg J. Confirming the continuum theory of dynamic brittle fracture for fast cracks. Nat 1999; 397: 333-335.

[4] Arakawa K, Mada T, Takahashi K. Correlations among dynamic stress intensity factor, crack velocity and acceleration in brittle fracture. Int J Fract 2000; 105: 311-320. 
1 [5] Évora VMF, Jain N, Shukla A. Stress intensity factor and crack velocity relationship for polyester/TiO2 nanocomposites. Exp Mech 2005; 45: 153-159.

3 [6] Gao HJ. Surface roughening and branching instabilities in dynamic fracture. J Mech Phys Solids 1993; 41: 457-486.

5 [7] Lee KH, Hawong JS, Choi SH. Dynamic stress intensity factors $K_{I}, K_{I I}$ and dynamic crack propagation characteristics of orthotropic material. Eng Fract Mech 1996; 53: 119-140.

7 [8] Landis CM, Pardoen T, Hutchinson JW. Crack velocity dependent toughness in rate dependent materials. Mech Mater 2000; 32: 663-678.

[9] Camacho M, Ortiz M. Computational modelling of impact damage in brittle materials. Int J Solids Struct 1996; 33: 2899-2938.

[10] Belytschko T, Organ D, Gerlach C. Element-free Galerkin method for dynamic fracture in concrete. Comput Methods Appl Mech Eng 2000; 187: 385-399.

[11] Duarte CA, Hamzeh ON, Liszka TJ, Tworzydlo WW. A generalized finite element method for the simulation of three-dimensional dynamic crack. Comput Methods Appl Mech Eng 2001; 190: 2227-2262.

[12] Remmers JJC, de Borst R, Needleman A. The simulation of dynamic crack propagation using the cohesive segments method. J Mech Phys Solids 2008; 56: 70-92.

[13] Freund LB. Dynamic fracture mechanics. New York: Cambridge University Press; 1990.

[14] Xie H, Sanderson DJ. Fractal effects of crack propagation on dynamic stress intensity factors and crack velocities. Int J Fract 1995; 74: 29-42.

[15] Krafft JM, Irwin GR. Crack velocity considerations. Fract Toughness Testing and Its Applications, ASTM STP 1965; 381: 114-129.

[16] Dally JW, Fourney WL, Irwin GR. On the uniqueness of stress intensity factor-crack velocity relationship. Int J Fract 1985; 27: 159-168.

[17] Pyo S, El-Tawil S. Crack velocity-dependent dynamic tensile behavior of concrete. Int J Impact Eng 2013; 55: 63-70.

[18] Graybeal BA. Material Property Characterization of Ultra-High Performance Concrete, Report No. FHWA-HRT-06-103, Federal Highway Administration, Washington, DC, 2006.

[19] Pfeifer CG, Moeser B, Giebson C, Stark J. Durability of ultra-high-performance concrete. Tenth ACI International Conference on Recent Advances in Concrete Technology and Sustainability Issues. No. SP-261-1, 2009. 
1 [20] Graybeal BA. Ultra-High Performance Concrete, Report No. FHWA-HRT-11-038, Federal 2 Highway Administration, Washington, DC, 2011.

3 [21] Graybeal BA. UHPC making strides, Public Roads, Federal Highway Administration, $4 \quad$ McLean, VA, 2009; 72: 17-21.

5 [22] Pyo S, Wille K, El-Tawil S, Naaman AE. Strain rate dependent properties of ultra high performance fiber reinforced concrete (UHP-FRC) under tension. Cem Concr Compos 2015;

8 [23] Pyo S. Characteristics of ultra high performance concrete subjected to dynamic loading. Ph.D. 9 Dissertation. University of Michigan, Ann Arbor, 2014.

[24] Wille K, Naaman AE, Parra-Montesinos GJ. Ultra-high performance concrete with compressive strength exceeding $150 \mathrm{MPa}$ (22 ksi): A simpler way. ACI Mater J 2011; 108 : 46-54.

[25] Pyo S, El-Tawil S. Capturing the strain hardening and softening responses of cementitious composites subjected to impact loading. Constr Build Mater 2015; 81: 276-283.

[26] John R, Shah SP, Jenq YS. A fracture mechanics model to predict the rate sensitivity of mode I fracture of concrete. Cem Concr Res 1987; 17: 249-262.

[27] Canny J. A computational approach to edge detection. IEEE Trans Pattern Anal Mach Intell 1986; 8: 679-698.

[28] Maini R, Aggarwal H. Study and comparison of various image edge detection techniques. Int J Image Process 2009; 3: 1-11.

[29] Shah SP. Determination of fracture parameters $\left(K_{I C}^{S}\right.$ and $\left.\mathrm{CTOD}_{\mathrm{c}}\right)$ of plain concrete using threepoint bend tests. Mater Struct 1990; 23: 457-460.

[30] Wardeh G, Ghorbel E. Prediction of fracture parameters and strain-softening behavior of concrete: effect of frost action. Mater Struct 2013; 1-16. DOI: 10.1617/s11527-013-0172-8.

[31] Trottier JF, Banthia N. Toughness characterization of steel-fiber reinforced concrete. J Mat Civ Eng 1994; 6: 264-289.

[32] Banthia N, Sappakittipakorn M. Toughness enhancement in steel fiber reinforced concrete through fiber hybridization. Cem Concr Res 2007; 37: 1366-1372.

[33] Kim DJ, Naaman AE, El-Tawil S. Comparative flexural behavior of four fiber reinforced cementitious composites. Cem Concr Compos 2008; 30: 917-928. 
1 [34] Kim DJ, Park SH, Ryu GS, Koh KT. Comparative flexural behavior of Hybrid Ultra High Performance Fiber Reinforced Concrete with different macro fibers. Constr Build Mater 2011; $325: 4144-4155$.

4 [35] Zhang X, Ruiz G, Elazim AMA. Loading rate effect on crack velocities in steel fiber-reinforced concrete. Int J Impact Eng 2015; 76: 60-66.

6 [36] Rayleigh L. On waves propagated along the plane surface of an elastic solid. Proc Royal Soc $7 \quad$ A $1885 ; 17: 4-11$.

8 [37] Vinh PC, Ogden RW. On formulas for the Rayleigh wave speed. Wave Motion 2004; 39: 1919

10 [38] Fineberg J, Gross SP, Marder M, Swinney HL. Instability in Dynamic Fracture. Phys Rev Lett 11 1991; 67: 457-460.

12 [39] Freund LB. Crack propagation in an elastic solid subjected to general loading-II. Nonuniform rate of extension. J Mech Phys Solids 1972; 20: 141-152. 